TRIBUNAL EUROPEO DE DERECHOS HUMANOS 



\title{
EL DERECHO A LA LIBERTAD DE EXPRESIÓN EN LA JURISPRUDENCIA DEL TRIBUNAL EUROPEO DE DERECHOS HUMANOS: DOS CASOS ESPAÑOLES ${ }^{1}$
}

\author{
ISABEL SERRANO MAÍLLO \\ Profesora de Derecho Constitucional \\ Universidad Complutense de Madrid
}

\author{
SUMARIO. \\ I. La libertad de expresión en el Convenio Europeo \\ II. Límites a la libertad de expresión según el \\ TEDH \\ III. El caso español
}

\section{LA LIBERTAD DE EXPRESIÓN EN EL CONVENIO EUROPEO}

La libertad de expresión se configura como un derecho fundamental en nuestro ordenamiento jurídico; especial consideración que también le otorga el Convenio para la Protección de los Derechos Humanos y de las Libertades Fundamentales². Esto es así porque como ha dejado sentado a lo largo de su jurisprudencia el Tribunal Europeo de De-

1 Este trabajo se enmarca dentro del proyecto de investigación Constitución y Globalización: transformaciones del Estado Constitucional y Constitucionalismo (DER2009-10375/JURI), subvencionado por el Ministerio de Educación y Ciencia.

2 Art. 10 del Convenio para la Protección de los Derechos Humanos y de las Libertades Fundamentales: «1 Toda persona tiene derecho a la libertad de expresión. Este derecho comprende la libertad de opinión y la libertad de recibir o de comunicar informaciones o ideas sin que pueda haber injerencia de autoridades públicas y sin consideración de fronteras. El presente artículo no impide que los Estados sometan las empresas de radiodifusión, de cinematografía o de televisión a un régimen de autorización previa. 2 El ejercicio de estas libertades, que entrañan deberes y responsabilidades, podrá ser sometido a ciertas formalidades, condiciones, restricciones o sanciones, previstas por la ley, que constituyan medidas necesarias, en una sociedad democrática, para la seguridad nacional, la integridad territorial o la seguridad pública, la defensa del orden y la prevención del delito, la protección de la salud o de la moral, la protección de la reputación o de los derechos ajenos, para impedir la divulgación de informaciones confidenciales o para garantizar la autoridad y la imparcialidad del poder judicial.» 
rechos Humanos, «la libertad de expresión es uno de los fundamentos de las sociedades democráticas, pues sólo a través de la libertad de expresión se puede crear una opinión pública libre y responsable, la cual a su vez es presupuesto necesario para el correcto funcionamiento de una democracia» ${ }^{3}$.

En el artículo 10 del Convenio, la libertad de expresión se articula como un derecho único que integra la libertad de opinión por un lado, y la de recibir o de comunicar informaciones, por otro ${ }^{4}$. No obstante, el TEDH ha destacado la necesidad de diferenciar entre hechos y opiniones, dado que el tratamiento no será igual si se trata de éstas que si se trata de aquéllos. Y esto, porque los hechos son susceptibles de prueba y se les puede exigir el requisito de veracidad, mientras que las opiniones no pueden ser comprobadas ni, por tanto, sometidas al control de la verdad.

No obstante, es importante matizar que el bien jurídico protegido por la libertad de expresión «no sería la libertad personal de opinar, sino la libertad de comunicar juicios o ideas. Esta puntualización es importante, dado que comunicar conlleva una carga informativa superior.» ${ }^{5}$. Esto implica que aunque no se les pueda exigir veracidad, «a las opiniones ha de exigírseles que se realicen con criterio o, al menos, con sinceridad. Asimismo, «incluso cuando una declaración equivale a un juicio de valor (...) debe tener suficiente base factual —coincidencia con el referente externo-, sin lo cual sería excesiva.» ${ }^{6}$

No es discutible la relevancia que este derecho tiene en toda sociedad democrática, pero tampoco lo es el hecho de que no pueda configurarse como absoluto. Lo que implica que estarán protegidas aquellas opiniones que, a pesar de suponer una intromisión en otros derechos fundamentales, guarden congruencia con esa finalidad última de la libertad de expresión, que es garantizar una opinión pública libre, es decir, que resulten relevantes para la formación de la misma sobre asuntos de interés general. Por el contrario, carecerán de tal efecto legitimador «cuando las libertades de expresión e información se ejerciten de manera desmesurada y exorbitante del fin en atención al cual la Constitución les concede su protección preferente» ${ }^{7}$.

\section{LÍMITES A LA LIBERTAD DE EXPRESIÓN SEGÚN EL TEDH.}

El Tribunal de Estrasburgo, a pesar de reconocer que la libertad de expresión no es un derecho absoluto, se ha mostrado muy estricto a la hora de permitir injerencias en el

3 SUÁREZ ESPINO, M. L.: «Los derechos de comunicación social en la jurisprudencia del Tribunal Europeo de Derechos Humanos y su influencia en el Tribunal Constitucional español», en la Revista de Derecho Constitucional Europeo de la Universidad de Granada, núm. 7, 2007, pág. 2.

4 SERRANO MAÍLLO, M.I.: «Las libertades informativas», en SÁNCHEZ GONZÁLEZ, S. (coord.). Dogmática y práctica de los derechos fundamentales, Tirant lo Blanch, Valencia, 2006, pág. 284, en relación al ordenamiento jurídico español: «Queda claro, por tanto, que ambas libertades son diferentes y que van a tener un distinto tratamiento jurídico. Se admite que la libertad de expresión es más amplia que la de información, pero no que ésta forme parte de aquella.»

5 GALVEZ MONTES, J.: «Artículo 20», en Comentarios a la Constitución, Editorial Fernando Garrido Falla, Madrid, 1980, pág. 401.

6 STEDH de 27 de febrero de 2001, caso Jerusalem contra Austria, párrafo 43.

7 STC 171/1990, de 12 de noviembre, FJ 6. 
mismo por parte de los Estados. Así, ha establecido claramente las condiciones que deben cumplir las medidas nacionales impuestas en este sentido para ser compatibles con el Convenio ${ }^{8}$. En primer lugar, se exige que la medida restrictiva esté prevista por la ley; en segundo lugar, que la limitación esté justificada por alguno de los fines establecidos en el apartado 2 del artículo 10 del Convenio 9 y, por último, que la medida sea necesaria dentro de una sociedad democrática.

Las dos primeras condiciones no presentan mayores complicaciones, ya que no conllevan ninguna operación que no sea más o menos automática. Así, en el primer caso el Tribunal solo debe contrastar la existencia efectiva de una ley nacional que recoja la limitación ${ }^{10} \mathrm{y}$, en el segundo, que la misma responda a la consecución de uno de los objetivos previstos en el art. 10.2 del Convenio ${ }^{11}$. La última condición, hace referencia a dos aspectos esenciales: la necesidad de la injerencia en una sociedad democrática y la proporcionalidad entre la medida y el objetivo que se persigue conseguir. Esta última operación «es sin duda la más conflictiva y en ella se cifra la resolución de los conflictos planteados ante el Tribunal» ${ }^{12}$. Por esta razón, nos centraremos en ella, obviando por el momento un comentario más extenso de las otras dos.

Necesidad de la injerencia.- De la jurisprudencia del TEDH se desprende que esta medida significa que la injerencia debe responder a una «necesidad social imperiosa $»^{13}$. Esto no significa que deba interpretarse como sinónimo de imprescindible, pero tampoco que se pueda justificar la injerencia por motivos de oportunidad o pertinencia, ni porque la misma resulte razonable. Es fundamental, en este punto, que las autoridades nacionales hagan una correcta valoración y ponderación de los intereses en conflicto (el derecho del individuo que se pretende restringir por un lado, y el fin que persigue el Estado con esa restricción, por otro), para poder asegurar que se produzca un justo equilibrio entre todos los intereses implicados en el caso ${ }^{14}$.

8 KORFF, D.: «The guarantee of freedom of expression under article 10 of the European Convencion on Human Rights, en Media Law and Practice, diciembre 1998, vol. 9, núm. 4, págs. 143-150.

9 Vid. Supra nota 1.

10 SUÁREZ ESPINO, op. cit., pág. 4: «Para constatar que se cumple con el requisito de la previsión legal, el TEDH se limita a comprobar que la injerencia en la libertad de expresión se recoge en alguna norma del ordenamiento jurídico de aquel Estado que pretende establecer la limitación».

11 MAGDALENO ALEGRÍA, A.: «Libertad de expresión y partidos políticos en la jurisprudencia del Tribunal Europeo de Derechos Humanos», en AFDUDC, núm. 11, 2007, en pág. 439, dice que «solo son objetivos legítimos aquellos enunciados expresamente en el párrafo $2^{\circ}$ del artículo $10 »$. Sensu contrario, SUÁREZ ESPINO, op. cit., pág 5, considera que «La lista que enumera el artículo 10.2 CEDH como fines que en principio legitimarían la imposición de restricciones a la libertad de expresión se caracteriza por su excesiva amplitud y por el empleo de nociones ambiguas, por lo que resulta relativamente sencillo clasificar cualquier medida limitativa en uno de los supuestos enumerados en el apartado segundo del artículo 10.»

12 GAY FUENTES, C.: «La jurisprudencia del Tribunal Europeo de Derechos del Hombre en materia de libertad de expresión y su aplicación por el Tribunal Constitucional español», en Revista de Administración Pública, núm. 120, 1989. Pág. 268.

13 STEDH de 25 de junio de 2002, Caso Colombani contra Francia, párrafo 57; STEDH de 7 de diciembre de1976, caso Handyside contra Reino Unido; STEDH de 8 de julio de 1986, caso Linges contra Austria, párrafo 39.

14 MAGDALENO ALEGRÍA, A., op.cit., pág. 441: «El TEDH considera que si se interpretan de manera amplia las limitaciones de la libertad de expresión, se corre el riesgo de que determinadas personas se autocensuren y no participen en los debates sobre cuestiones de interés público por miedo a sufrir sanciones». 
Proporcionalidad ${ }^{15}$. - Esta medida exige la comprobación de que las ventajas que se obtienen con la injerencia en el derecho fundamental compensan los sacrificios que ésta implica para sus titulares y para la sociedad en general. Si no es así, o existe un medio menos gravoso para el derecho fundamental en cuestión con el que se consiga el mismo fin, se entenderá que no se cumple el requisito de proporcionalidad. En este punto debemos avanzar que el TEDH se ha mostrado, de forma general, muy reacio a admitir condenas penales como castigo a las ofensas contra el honor, entendiendo que existen medidas menos gravosas y que, por tanto, la aplicación de este tipo de condenas rompe con el principio de proporcionalidad que se exige. No obstante, como veremos más adelante, admite ciertas excepciones en relación al contenido de las declaraciones del condenado en sede nacional.

La doctrina del margen de apreciación ${ }^{16}$. - A pesar de que este principio no ha sido formulado expresamente en el Convenio Europeo ${ }^{17}$, se admite que los Estados gocen de cierta libertad a la hora de restringir algunos derechos fundamentales. Aunque la última palabra la tendrá el TEDH (en última instancia, ejercerá el control sobre las injerencias estatales para determinar si son admisibles o no), éste entiende que hay ciertas cuestiones sobre las que es más adecuado que decida el Estado nacional por ser mejor conocedor de la realidad de su país. Así, el margen de apreciación será mayor o menor dependiendo del grado de uniformidad existente sobre un concepto determinado en las legislaciones de los países firmantes del Convenio. Sobre aquellas cuestiones en las que haya menos consenso, por su condicionamiento por factores sociales o culturales, los Estados tendrán un mayor margen de apreciación, mientras que en los que exista gran uniformidad, el margen de apreciación será muy reducido o, incluso, inexistente. Así, por ejemplo, será muy amplio en casos relacionados con la moral y, muy limitados en asuntos concernientes a la imparcialidad judicial. Este margen de apreciación está especialmente restringido en los casos relativos a la libertad de expresión, lo que ha explicado reiteradamente el TEDH, basándose en que este derecho, es uno de los pilares fundamentales de las sociedades democráticas. De ahí que no se pueda dejar al libre arbitrio de las autoridades nacionales el establecimiento de límites que puedan llegar a ahogar esa libertad.

15 BERNAL PULIDO, C.: El principio de proporcionalidad y los derechos fundamentales, CEPC, Madrid, 2007, pág. 523: «el principio de proporcionalidad debe ser definido como un límite de los límites a los derechos fundamentales». BARNÉS VÁZQUEZ, J.: «El principio de proporcionalidad. Estudio preliminar», Cuadernos de Derecho Público, núm. 5, 1998, pág. 16.: «el principio de proporcionalidad está integrado por un conjunto de criterios o herramientas que permiten medir y sopesar la licitud de todo género de límites normativos de las libertades, así como la de cualesquiera interpretaciones o aplicaciones de la legalidad que restrinjan su ejercicio»

16 MAGDALENO ALEGRÍA, A., op.cit., pág. 439: «Esta doctrina es una técnica jurisdiccional de resolución de conflictos, dirigida a delimitar la competencia de los órganos jurisdiccionales del Convenio para verificar la aplicación de algunas de las disposiciones dirigidas a derogar el goce de los derechos y libertades reconocidos en el mismo». Sobre este tema ver también MONTFIELD, H., «The concept of Lawful Interference with Fundamental Rights», en Understanding Human Rights Principles, Hart Publishing, Oxford y Portland, 2001, págs. 5-25. GARCÍA ROCA, J., El margen de apreciación nacional en la interpretación del Convenio Europeo de Derechos Humanos: Soberanía e integración, Aranzadi, 2010.

17 YOUROV, H. Ch.: The margin of apreciation doctrine in the dynamics of European Human Rights jurisprudence, La Hyaa/Boston/Londres, Kluwer Press, 1996. 


\section{EL CASO ESPAÑOL}

Recientemente, el TEDH ha pronunciado dos sentencias en las que condena al Estado español por vulnerar el artículo 10 del Convenio, es decir, por vulnerar el derecho a la libertad de expresión de un periodista, por un lado, y de un político por otro. Aunque analizaremos detenidamente cada uno de estos casos, creemos conveniente adelantar que, si bien compartimos sin matices la decisión adoptada en el primero de los casos, no estamos en absoluto de acuerdo con la condena que recayó en el caso de Otegui contra España. En las dos resoluciones, el Tribunal pareció adoptar una postura acorde con la jurisprudencia sentada en los casos de conflictos entre la libertad de expresión y el derecho al honor de las personas públicas. Pero creemos que mientras en el caso del periodista llegó a una conclusión coherente y consecuente con esa línea marcada por él mismo, no sucedió lo mismo en el caso del político.

Importa señalar que, a pesar de que ambas sentencias condenaron la violación de la libertad de expresión del art. 10 del Convenio, se trata de casos que se refieren a distintas vertientes de dicho derecho. En el primero, nos situaríamos en el ámbito del derecho a difundir información (lo que llamamos, en nuestro ordenamiento interno, derecho a la información), mientras que en el segundo nos encontraríamos ante el ejercicio del derecho a difundir ideas, opiniones o juicios de valor. Es importante hacer esta apreciación, pues como ya se ha apuntado, se puede y se debe exigir al ejercicio del derecho de información el requisito de veracidad, mientras que en materia de opinión tal exigencia no es pertinente.

\section{A) STEDH de 1 de junio de 2010, caso José Luis Gutiérrez contra España ${ }^{18}$}

Este caso trae causa de una demanda interpuesta por el entonces Rey de Marruecos, Hassan II, contra el Diario 16, por considerar que una noticia publicada por este periódico vulneraba su honor ${ }^{19}$. El periodista, director del medio en aquel momento, fue condenado por todas las instancias judiciales nacionales ${ }^{20}$. Y el Tribunal Constitucional español ratificó la condena al desestimar el recurso de amparo.

18 GUTIÉRREZ, J. L.: En defensa propia, Saber y Comnunicación, S.L, 2005. En esta obra, el autor narra el caso y todo el periplo judicial nacional.

19 STEDH de 1 de junio de 2010, Caso Gutiérrez contra España, párrafo 6: «El 18 de diciembre de 1995, el diario de tirada nacional «Diario 16» (...) publicó en primera página, una noticia relativa a la incautación en Algeciras de 4.638 kilogramos de hachís ocultos en el doble fondo de un camión de la Sociedad «Domaines Royaux» propiedad de la familia real alauí y que se dedicaba a la exportación de cítricos y frutas tropicales. (...) El artículo aparecía en primera página con el título «Una empresa familiar de Hassan II involucrada en el tráfico de drogas». En la página 12 se publicó otro artículo (...): «Se descubren cinco toneladas de hachís en un cargamento de la empresa de Hassan II». En el texto del artículo se mencionaban varios artículos publicados en «El Mundo», «Le Monde» y «Herald Tribune», en los que se decía que el tráfico de drogas era la principal fuente de divisas de Marruecos, y se apuntaba a algunos políticos marroquíes próximos al monarca».

20 El Juzgado de Primera Instancia de Madrid condenó, mediante resolución de 25 de noviembre de 1997, al periodista, al director del periódico y a la editorial, por una intromisión ilegítima en el derecho al honor de Hassan II, al considerar que la información era falsa. La audiencia Provincial, mediante resolución de 21 de enero de 1999, rechazó el recurso y confirmó en su integridad la resolución del Juzgado de Primera Ins- 
Como es sabido, tanto la jurisprudencia constitucional española como la del TEDH, coinciden en la necesidad de exigir que las informaciones cumplan los requisitos de veracidad e interés público, a fin de que puedan ser consideradas prevalentes en caso de conflicto con otro derecho fundamental. Esto es así porque el fin último del derecho a comunicar información es crear una opinión pública libre ${ }^{21}$, lo que solo es posible si se basa en noticias que cumplan estos dos requisitos, y no cuando se trate de difundir mentiras o simples rumores.

El problema es que no es fácil determinar qué es el interés público ${ }^{22}$. Se trata de un concepto considerado por la jurisprudencia constitucional y por nuestra doctrina como jurídicamente indeterminado. Según Núñez Ladeveze, es de interés público aquella información que «procede de la objetivación de las relaciones políticas y de la interacción $\operatorname{social}^{23}(\ldots)$ el interés público emana de la condición política de la persona en cuanto forma parte de una comunidad en que los intereses individuales han de adaptarse a un interés común (...). Este interés público es distinto del interés del público por acontecimientos que genéricamente conmueven a la mayoría de las personas por motivos principalmente psicológicos ${ }^{24} »$. A pesar de la dificultad que supone definir el concepto que nos ocupa y determinar, en ciertas ocasiones, si nos encontramos o no ante una información verdaderamente relevante, lo cierto es que en ningún momento a lo largo del proceso judicial se puso en duda la relevancia de la información. Todos los tribunales consideraron que se trataba de una información de gran interés dados el contenido ${ }^{25}$ y los sujetos protagonistas del asunto. Así lo creyó también el TEDH, para el que la prensa juega un papel de especial relevancia en las sociedades democráticas, informando de todos

tancia, al considerar que la información no era cierta. El Tribunal Supremo, por resolución de 24 de junio de 2004, desestimó el recurso interpuesto al considerar, no que la información fuera inveraz o falta de interés público, sino que la ofensa se producía en los titulares. Esto porque podían hacer «que el lector medio creyera que la familia real marroquí había sido cómplice en el tráfico ilegal de hachís» (párrafo 10).

21 SÁNCHEZ DE DIEGO FERNÁNDEZ DE LA RIVA, M., «Concentración informativa y libertad de información», en FARIAS GARCÍA, P. y SÁNCHEZ DE DIEGO FERNÁNDEZ DE LA RIVA, M. (Coords.)., Las libertades informativas en el mundo actual, Madrid, Facultad de Ciencias de la Información, Universidad Complutense de Madrid, 1999, pág. 520., dice que el concepto de opinión pública libre y plural va a servir como causa de justificación de la prevalencia de la libertad de información sobre los otros derechos. [...] si en una sociedad no se puede apreciar que la opinión pública es libre y, por tanto, plural, no existe auténtica libertad de información. O mejor dicho, la existencia de mayor o menor libertad de información se encuentra en relación directa con el grado de libertad y pluralismo que exista en la opinión pública».

22 MUÑOZ MACHADO, S., Libertad de prensa y procesos por difamación, Barcelona, Ariel, 1988, pág. 152: «La relevancia pública de la información es uno de los límites internos que condicionan y legitiman el ejercicio de la libertad de información (...) porque de este límite se deduce la contribución de la información a la formación de la opinión pública».

23 NÚÑEZ LADEVEZE, L., El lenguaje de los media, Madrid, Pirámide, 1979, págs. 76 a 84.

24 NÚÑEZ LADEVEZE, L., Manual de periodismo, Barcelona, Ariel, 1991, pág. 40.

25 STEDH de 1 de junio de 2010, caso Gutiérrez contra España, párrafo 34: «el Tribunal puede admitir que la información controvertida es de interés general, a saber, el público español (...) tienen derecho a ser informados sobre un tema como un tráfico de drogas en el que parece estar cuestionada la familia real de Marruecos y el propio Rey de Marruecos, y ello a pesar de que la posible infracción no se haya cometido, en principio, en el ejercicio de sus funciones políticas. (...) El Tribunal reitera, a estos efectos, que no puede pensarse que las cuestiones planteadas a los tribunales (...) no pueden antes o al mismo tiempo, suscitar un debate en otros lugares». En el mismo sentido ver STEDH de 22 de noviembre de 2005, caso Tourancheau y July contra Francia, párrafo 66. 
aquellos asuntos de interés general, a pesar de que a veces pueda resultar molesto para alguno de los sujetos implicados. Además, como ha afirmado reiteradamente, si no se concediera ese estatus especial a la prensa, «no podría desempeñar su indispensable papel de perro guardián» ${ }^{26}$.

El otro sujeto implicado, era el Rey de Marruecos, un personaje de indudable proyección pública. Respecto a la protección de los derechos de la personalidad de este tipo de sujetos, el TEDH se ha pronunciado en múltiples ocasiones (lo ha hecho en la misma línea que el Tribunal Constitucional español ${ }^{27}$ ), en el sentido de considerar que si bien sus derechos deben gozar de protección, esta será menor que si se tratara de una persona anónima ${ }^{28}$ porque «un político se expone de forma inevitable y consciente a un estrecho control de sus acciones y de sus gestos, tanto por parte de los periodistas como por parte del público en general, y deben — consecuentemente- mostrar mayor tolerancia» ${ }^{29}$.

El único elemento controvertido fue la veracidad, aunque como sostuvo el TEDH «ni el fallo del Tribunal Supremo ni la decisión del Tribunal Constitucional negaron que el contenido de la información publicada se correspondiera, en lo esencial, con la reali$\operatorname{dad} »^{30}$.

Una vez expuestos los antecedentes del caso en cuestión, el Tribunal procedió a comprobar si la injerencia en la libertad de expresión llevada a cabo por España fue pertinente a la luz de las exigencias del TEDH, es decir, si — como apuntábamos en el apartado II de este trabajo - superaba el denominado test de Estrasburgo; es decir, que la medida restrictiva estuviera prevista por la ley, que la restricción estuviera justificada por alguno de los fines establecidos en el apartado 2 del artículo 10 del Convenio ${ }^{31}$; y que la medida fuera necesaria en el ámbito de una sociedad democrática. Los dos primeros requisitos se cumplían, porque la restricción estaba recogida en el artículo 18 de la CE y la L.O 1/82 de 5 de mayo, y porque se pretendía proteger la reputación ajena, uno de los fines admitidos por el art. 10.2 del Convenio. Pero no ocurría lo mismo con la adecuación de la

26 STEDH de 1 de junio de 2010, caso Gutiérrez contra España, párrafo 25; STEDH de 25 de junio de 1992, caso Thorgeir contra Islandia, párrafo 63; STEDH de 20 de mayo de 1999, caso Tromso Bladet y Stensaas contra Noruega, párrafo 62.

27 STC 174/06 (FJ 4): «Los límites permisibles de la crítica son más amplios si ésta se refiere a personas que, por dedicarse a actividades públicas, están expuestas a un más riguroso control de sus actividades y manifestaciones que si se tratase de simples particulares sin proyección pública alguna, pues, en un sistema inspirado en los valores democráticos, la sujeción a esa crítica es inseparable de todo cargo de relevancia pública». Ver también SSTC 159/86 (FJ 6), 20/02 (FJ 5) o 151/04 (FJ 9), entre otras.

28 CARRERAS SERRA, L. de, Régimen jurídico de la información, Barcelona, Ariel, 1996, pág. 53: «una persona de relevancia pública, por ocupar una posición especial de poder en el ámbito social o por ser un servidor de la cosa pública, es más noticiable [...] Cuando no intervienen estas personas, la trascendencia pública la ha de tener el hecho en sí mismo, con independencia de las personas privadas que en él tomen parte»

29 STEDH de 1 de junio de 2010, caso Gutiérrez contra España, párrafo 26. Continúa diciendo: «Ciertamente tiene derecho a que se proteja su reputación, incluso fuera del contexto de su vida privada, pero debe encontrarse el equilibrio entre los requisitos para dicha protección y los intereses de la discusión abierta sobre temas políticos».

30 STEDH de 1 de junio de 2010, caso Gutiérrez contra España, párrafo 34 continúa: «(...) en ningún caso mencionaron que los datos que aparecían en el artículo de prensa hubieran sido inexactos, sino que hacían referencia a los titulares del artículo en cuestión y, por otra parte, al hecho de que dicho artículo omitía ciertos datos relativos a los procedimiento penales y judiciales abiertos».

31 Vid. Supra nota 1. 
medida, que como se indicó, debía responder a una necesidad social imperiosa ${ }^{32}$, resultar proporcionada y que los motivos aducidos por la autoridades nacionales fueran pertinentes. Así pues, y teniendo en cuenta que la noticia era veraz y de interés público y que no se demostró mala fe en los informadores ${ }^{33}$, el TEDH estimó que dicha información era digna de protección y, en consecuencia, debía prevalecer en caso de conflicto. En suma, que la limitación impuesta en este caso era excesiva, e incurría en una violación del artículo 10 del Convenio.

Llegados a este punto, nos parece interesante hacer referencia a ciertas cuestiones que destacó el TEDH en relación con el ejercicio del periodismo. La primera se refería a los titulares de la información y la segunda a las fuentes informativas. Obviamente, el TEDH hizo referencia a estos temas en respuesta a la sentencia de nuestro Tribunal Supremo $^{34}$ y al Auto del Tribunal Constitucional ${ }^{35}$ español, quiénes se ampararon en estos elementos para justificar su injerencia en el derecho a la libertad de información de los periodistas.

Los tribunales españoles establecieron que la vulneración del derecho al honor no se producía en el texto de la información, sino en los titulares de la misma, a lo que el TEDH replicó que no es labor de los tribunales de Justicia ni de los órganos jurisdiccionales nacionales establecer qué técnicas periodísticas deben utilizar los medios para dar sus noticias, sino que es la prensa misma la que decide cómo dar sus informaciones ${ }^{36}$. Y recordó, en relación a los titulares, que: «su finalidad es llamar la atención de los lectores sobre los hechos expuestos en el cuerpo de la información (...) (que) es necesario leer la información del título y el contenido en su conjunto, teniendo en cuenta tanto la ve-

32 STEDH de 25 de junio de 2002, caso Colombani contra Francia, párrafo 57: «la necesidad de alguna restricción en el ejercicio de la libertad de expresión debe quedar probada de manera convincente. Corresponde en primer lugar a las autoridades nacionales evaluar si existe una «necesidad social imperiosa» que justifique dicha restricción, ejercicio por el cual gozan de cierto margen de apreciación. Cuando se trata de la prensa, el poder de apreciación interno se enfrenta al interés de la sociedad democrática de asegurar y mantener la libertad de prensa».

33 STEDH de 1 de junio de 2010, caso Gutiérrez contra España, párrafo 35: «El Tribunal recuerda que, por razón de los «deberes y responsabilidades» derivados del ejercicio de la libertad de e expresión, la garantía que el artículo 10 proporciona a los periodistas con respecto a la presentación de informes sobre cuestiones de interés general quedan sujetos a la condición de que actúen de beuna fe con la finalidad de proporcionar información veraz y confiable con pleno respeto de la deontología periodística».

34 STS de 24 de junio de 2004: Los titulares de la información «hacían que el lector medio creyera que al familia real marroquí había sido cómplice en el tráfico ilegal de hachís».

35 ATC 411/2006, de 15 de noviembre (FJ 3): «En el caso actual el artículo en cuestión se anunciaba en primera página con el titular «una empresa familiar de Hassan II implicada en el narcotráfico». Este Tribunal ya ha reconocido anteriormente el decisivo papel que corresponde a los titulares de prensa en la transmisión de una noticia y en la subsiguiente configuración de la opinión pública. Ello es así, en principio, porque los potenciales destinatarios del titular son mucho más numerosos que los lectores de la propia noticia. Una circunstancia que se acrecentará cuando el titular se inserte en la portada de la publicación (STC 54/2004, de 15 de abril, FJ 8). Como señalábamos en la STC 178/1993, de 13 de octubre, la protección constitucional de la información se extiende a la noticia, que no pasa de ser mero relato de hechos encabezado por un titular igualmente limitado a narrar hechos con la brevedad usual de los titulares (FJ 3), pero no puede amparar titulares que, con la eficacia que les proporciona su misma brevedad estén destinados a sembrar en el gran público dudas sobre la honorabilidad de las personas aludidas».

36 STEDH de 1 de junio de 2010, caso Gutiérrez contra España, párrafo 36. En el mismo sentido STEDH de 20 de mayo de 1999, caso Tromso Bladet y Stensaas contra Noruega, párrafo 63. 
racidad de los hechos como el efecto de llamar la atención de los lectores que busca el título. (...) (y que) la libertad de prensa también abarca el posible recurso a un cierto grado de exageración o incluso de provocación ${ }^{37}$. Parece claro, por tanto, que no resulta adecuado fundamentar la falta de veracidad de la información únicamente en el titular, pues debemos entender que el mismo tiene como función el llamar la atención del lector y dirigirle hacia la lectura de la noticia.

En cuanto a las fuentes informativas, nuestra jurisprudencia constitucional es clara en cuanto al hecho de que es uno de los elementos esenciales en la búsqueda de la verdad informativa, pero para que sirvan como prueba evidente de veracidad, es necesario que sean absolutamente fidedignas y fiables ${ }^{38}$. De no ser así y tratarse de fuentes indeterminadas, la sola remisión a ellas no será suficiente prueba de veracidad ${ }^{39}$, aunque puedan servirnos como indicadores del camino a seguir en nuestra investigación para llegar, por otros medios, a la verdad. Esta parece ser la línea seguida por el TEDH, cuando dice que «los medios de comunicación (...) deben poder confiar en fuentes anónimas y no renovadas, sin tener que llevar a cabo investigaciones independientes, siempre que la información difundida sea veraz. De lo contrario, la prensa podría ser menos capaz de jugar su indispensable papel de «perro guardián $»^{40}$.

\section{B) STEDH de15 de marzo de 2011, caso Arnaldo Otegui contra España}

El caso que se nos plantea en esta sentencia es muy diferente al expuesto más arriba, a pesar de que puedan existir entre ellos algunas similitudes. En este supuesto nos encontramos ante un conflicto entre la libertad de expresión —en su vertiente de derecho a expresar ideas, opiniones y juicios de valor- de un representante político, por un lado, y el derecho al honor de una persona pública, el Rey de España, por otro. Este litigio ${ }^{41}$

37 STEDH de 1 de junio de 2010, caso Gutiérrez contra España, párrafo 36; En el mismo sentido STEDH de 20 de mayo de 1999, caso Tromso Bladet y Stensaas contra Noruega, párrafo 59 y STEDH de 26 de abril de 1995, caso Prager y Oberschlick contra Austria, párrafo 59.

38 STC 178/93 (FJ 5): «Cuando la fuente que proporciona la noticia reúne las características objetivas que la hacen fidedigna, seria o fiable, puede no ser necesaria mayor comprobación que la exactitud de la fuente»

39 STC 21/00 (FJ 8): «la remisión a fuentes indeterminadas resulta insuficiente para dar por cumplida la diligencia propia del informador»

40 STEDH de 1 de junio de 2010, caso Gutiérrez contra España, párrafo 38; En el mismo sentido STEDH de 27 de agosto de 1992, caso Tomasi vs. Francia párrafo 39).

41 STEDH de 15 de marzo de 2011, caso Arnaldo Otegui contra España, párrafos 8 a 10: «El 21 de febrero de 2003 (...) se registraron y posteriormente cerraron los locales del diario Euskaldunon Egunkaria, por causa de la presunta vinculación del periódico con ETA. Diez personas fueron arrestadas (...) los interesados se quejaron de haber sufrido malos tratos durante su detención. (...) el Rey de España fue recibido por el Presidente del Gobierno de la Comunidad Autónoma Vasca para participar en la inauguración de una central eléctrica en la provincia de Vizcaya. Durante una conferencia de prensa celebrada el mismo día en San Sebastián, el demandante, como portavoz del grupo parlamentario Sozialista Abertzaleak (...) afirmó, refiriéndose a la visita del rey al País Vasco, que «[era] patético» y que era una «sinvergonzada política» que el presidente del Gobierno Vasco inaugurara el proyecto (...) con Juan Carlos de Borbón, indicando que «esta imagen vale más que mil palabras». (...) Se expresó en estos términos: «¿Cómo es posible que se fotografíen hoy en Bilbao con el rey de España cuando el rey de España es el jefe supremo del Ejército español, es decir, el responsable de los torturadores y el que protege la tortura e impone su régimen monárquico a nuestro pueblo por medio de la tortura y la violencia?» 
trae causa de una querella interpuesta de oficio por la Fiscalía española contra Arnaldo Otegui, portavoz por aquel entonces de Sozialista Abertzaleak, por vulnerar el honor del Rey de España con unas declaraciones hechas en una rueda de prensa en las que tildaba a Don Juan Carlos de ser «el responsable de los torturadores» y de proteger «la tortura» e imponer su régimen monárquico (...) por medio de la tortura y la violencia».

Otegui fue absuelto por el Tribunal Superior de Justicia del País Vasco ${ }^{42}$ y condenado posteriormente por el Tribunal Supremo como autor de un delito de injurias graves al Rey ${ }^{43}$, sentencia que fue ratificada por el Tribunal Constitucional, que desestimó el Recurso de Amparo del demandante ${ }^{44}$. El TEDH, por su parte, determinó que la injerencia en la libertad de expresión de Otegui por parte del Estado español no había respondido a una necesidad social imperiosa por ser la pena desproporcionada al fin que se perseguía, razón por la cual se condenó a España ${ }^{45}$.

En cuanto al obligado cumplimiento de los requisitos exigidos por el test de Estrasburgo y como es habitual, los dos primeros no suponían ningún problema - la injerencia estaba prevista por la ley (art. 490.3 del Código penal español ${ }^{46}$, y perseguía alguno de los objetivos establecidos en el art. 10.2 del Convenio (la protección de la reputación, en este caso, del Rey de España) ${ }^{47}$ — , siendo la tercera medida (que la injerencia sea necesaria en una sociedad democrática), la que dio lugar a la controversia.

En este caso, para determinar la necesidad social imperiosa, hemos de contemplar todos aquellos elementos que puedan llevarnos a tomar la decisión más adecuada.

42 STSJ de 18 de marzo de 2005: «la crítica de una institución constitucional no está excluida del derecho a la libertad de expresión, y en tales casos éste adquiere, frente al derecho al honor, el carácter de un derecho constitucional prevalerte en tales materias».

43 STEDH de 15 de marzo de 2011, caso Otegui contra España, párrafo 16, resume la postura expresada en la STS de 31 de octubre: «expresaban un desprecio al Rey y la Institución que representa, afectando al núcleo mismo de su dignidad al atribuirle una de las manifestaciones delictivas más graves en un Estado de Derecho. El ejercicio del derecho a la libertad de expresión resultaba por lo tanto contrario al principio de proporcionalidad y era innecesario, rebasando el umbral a partir del cual se puede considerar que nos hallamos en presencia de críticas ofensivas o molestas».

44 ATC 213/2006, de 3 de julio (FJ 7): «Siendo cierto que la Constitución no veda, en cualesquiera circunstancias, el uso de expresiones hirientes, molestas o desabridas, también lo es que de la protección constitucional que otorga el art. 20.1 a) CE están excluidas las expresiones absolutamente vejatorias; es decir, aquéllas que, dadas las concretas circunstancias del caso, y al margen de su veracidad o inveracidad, sean ofensivas u oprobiosas y resulten impertinentes para expresar las opiniones o informaciones de que se trate».

45 STEDH de 15 de marzo de 2011, caso Otegui contra España, párrafo 61: «A la vista de cuanto antecede, e incluso admitiendo la pertinencia de los motivos invocados por las jurisdicciones internas, éstos no son suficientes para demostrar que la ingerencia denunciada era «necesaria en una sociedad democrática». Pese al margen de apreciación de las autoridades nacionales, el Tribunal considera que la condena del demandante no guarda proporción con el fin perseguido.»

46 Artículo 490.3 CP: «El que calumniare o injuriare al Rey o a cualquiera de sus ascendientes o descendientes, a la Reina consorte o al consorte de la Reina, al Regente o a algún miembro de la Regencia, o al Príncipe heredero de la Corona, en el ejercicio de sus funciones o con motivo u ocasión de éstas, será castigado con la pena de prisión de seis meses a dos años si la calumnia o injuria fueran graves, y con la de multa de seis a doce meses si no lo son».

47 Desde mi punto de vista, la injerencia también perseguí la defensa de la seguridad nacional y el orden público, otros de los objetivos recogidos en el art. 10.2 del Convenio y que debieron ser alegados por los tribunales españoles, pues el suceso va claramente más allá del insulto del Rey. 
En primer lugar hemos de tener en cuenta que el conflicto se produjo entre dos personas públicas. Un de ellos representante político y, el otro, el Rey de la nación, representante de todos los españoles. Constituye sentada jurisprudencia del TEDH la de que las personas públicas han de soportar mayores críticas que las personas anónimas, por estar más expuestos al control social y periodístico ${ }^{48}$, pero también lo es que este sacrificio no implica que las personas públicas no gocen del derecho al honor. Significa que «disfrutan también de esta protección, incluso cuando no actúan en el marco de su vida privada, pero las exigencias de esta protección deben equilibrarse con los intereses de la libre discusión de las cuestiones políticas» ${ }^{49}$. Debe advertirse, que aunque el Rey sea una persona pública, no deberíamos incluirlo en la categoría de político, dado que «no se encuentra dentro de la disputa política, ni está previsto que a lo largo de su vida participe en ella. Es más, sus actos — salvo contadas ocasiones - son necesariamente refrendados ${ }^{50}$ de la forma establecida en el art. $64 \mathrm{CE}$, ya que carece de responsabilidad. El Rey no es un actor político, representa al pueblo español... ${ }^{51}$.

Otegui, por su parte, sí actuaba como representante político en el momento de producirse las declaraciones objeto de litigio. Unas opiniones a las que el TEDH otorgó un valor superior por haber sido realizadas por un cargo público ${ }^{52}$. El Tribunal consideró que la libertad de expresión es especialmente valiosa en manos de estos sujetos, dado que en definitiva han sido elegidos por el pueblo y por tanto, hemos de entender que «representan a sus electores, señalan sus preocupaciones y defienden sus intereses ${ }^{53}$. Por esta causa, el TEDH se muestra muy reticente a la hora de admitir restricciones a la libertad de expresión de los políticos, especialmente cuando éstas conllevan una condena penal. Bien es cierto que, en ciertas ocasiones sí ha admitido las injerencias por parte de los Estados llegando a aceptar, incluso, la imposición de condenas penales ${ }^{54}$.

48 STEDH de 27 de mayo de 2004, caso Vides Aizsardzibas Klubs contra Letonia, párrafo 40; STEDH de 28 de septiembre de 2000, caso Lopes Gomez da Silva contra Portugal, párrafo 30; STEDH de 21 de enero de 1999, caso Janowski contra Polonia, párrafo 33.

49 STEDH de 8 de julio de 1986, caso Linges contra Austria, párrafo 42.

50 La necesidad de que los actos del Rey sean refrendados, indica que el Rey es más una figura representativa que en realidad no controla ni dirige ninguna parcela del quehacer político español. Por ello no se le puede considerar, en ningún caso, responsable de los excesos cometidos por los cuerpos de seguridad del Estado, que dependen del Ministerio del Interior, pero nunca del Rey. Muy diferente es el caso de Hassan II, que en el momento de producirse la notica de la que trae causa la primera de las sentencias comentadas, era el Rey de Marruecos, un Rey con un gran poder político, un Rey muy cercano a lo que conocemos como un monarca absoluto, por lo que sus responsabilidades morales y políticas debían ser acordes al poder que le daba su cargo. Como puede observarse, las situaciones de ambos monarcas son absolutamente diferentes.

51 SÁNCHEZ DE DIEGO FERNÁNDEZ DE LA RIVA, M.: «Las injurias al rey a la luz de la jurisprudencia del TEDH», en Revista Iustel, 2011, en prensa. «El Rey de España no ha accedido a ese rol público de forma voluntaria, a través de una elecciones como sí hacen los verdaderos representantes políticos, sino que su condición viene dada por el único rol al que, en nuestro días, se accede automáticamente: la sucesión a la corona regulado en la Constitución o en la Ley de Sucesión correspondiente. Responde a la máxima acuñada por los británicos de que el rey nace y no se hace».

52 STEDH de 8 de julio de 1986, caso Linges contra Austria: «el TEDH también ha entendido que la libertad de expresión de los cargos públicos debe ser especialmente garantizada, controlándose muy rigurosamente las posibles injerencias en la libertad de expresión de las personas que ejercen cargos públicos»

53 STEDH de 23 de abril de 1992, caso Castell contra España, párrafo 42.

54 STEDH de 16 de julio de 2009, caso Féret contra Bélgica; STEDH 16 de julio de 2009, caso Willem contra Francia; STEDH de 23 de abril de 1992, caso Castell contra España, párrafo 46: «la posición dominante 
En otro orden de cosas, parece que el TEDH no tuvo en cuenta las circunstancias que rodeaban a Otegui, ni aquellas en las que se produjeron las declaraciones, algo, a nuestro juicio, fundamental a la hora de determinar si la injerencia estaba amparada por el art. 10 del Convenio o no. Así, creemos que el Tribunal Europeo debió tomar en consideración, además del hecho de que Otegui era un representante político, que el acto se desarrolla en un ambiente de actividad terrorista y que, cuando sucedieron los hechos, se estaba llevando a cabo un proceso mediante el que HB, Batasuna y Euskal Erritarrok, terminarían siendo ilegalizados por formar parte del entramado de ETA (decisión que fue ratificada por el Tribunal Constitucional español y por el TEDH). Las declaraciones de Otegui no se produjeron, pues, en un ambiente político normal, sino en un contexto enrarecido por la violencia terrorista, uno de cuyos protagonistas era precisamente él. Detalle éste en el que el TEDH debió reparar, ya que en su jurisprudencia este tipo de contextos se convierte en un factor importante dentro de su doctrina sobre la libertad de expresión de los representantes políticos. Así lo ha puesto de relieve Jesús María Santos Vijande, al resaltar que el Tribunal de Estrasburgo ha manifestado respecto a este asunto que «las declaraciones de las personalidades de la actividad política, si bien han de gozar de la máxima amplitud para preservar la entraña misma del sistema democrático, por esa misma razón han de ser enjuiciadas con singular rigor, cuando, en un ambiente de terrorismo, puedan poner en peligro el orden democrático, negándole su legitimidad. Se busca, en definitiva, que el político no pueda prevalerse de las libertades que la democracia le otorga para subvertir desde dentro el sistema democrático» ${ }^{55}$.

Es obvio que esto deba ser así, pues los representantes políticos tienen un mayor acceso a los medios de comunicación y sus mensajes, por tanto, tienen una mayor difusión. Por ello, se les debe exigir cierta responsabilidad en relación con las opiniones y juicio de valor que manifiestan. Recordemos que si bien ni estos ni aquéllas pueden ser fiscalizados desde la óptica de la veracidad, sí debe exigírseles que tengan «suficiente base factual - coincidencia con el referente externo-, sin lo cual sería excesiva» ${ }^{56}$.

Desde nuestro punto de vista, las manifestaciones realizadas por Otegui contra el Rey de España no tenían esa base factual y fueron excesivas, vulnerando claramente el honor del monarca. No se fundamentaban en datos reales, no solo por la falta de capacidad del Rey de llevar cabo los actos que se le imputaban, sino porque además, las denuncias por tortura a las que se refería Otegui resultaron ser falsas ${ }^{57}$. Sostuvo, además el Tribunal, respecto a las declaraciones, que éstas «no afectaban a la vida privada del Rey (...) o su honor personal, y que no comportaban un ataque personal gratuito contra su persona» ${ }^{58}$. ¿Cómo puede pretenderse que ser acusado de torturador no afecta al honor personal,

que ocupa le exige mostrar moderación en el recurso a la vía penal, sobre todo cuando existan otros medios de responder a los ataques y críticas injustificadas de sus adversarios o de los medios de comunicación. Pero no deja de resultar lícito para las autoridades competentes del Estado la adopción, en su condición de garante del orden público, de medidas, incluso penales, destinadas a reaccionar de manera adecuada y no excesiva contra acusaciones difamatorias desprovistas de fundamento o formuladas con mala fe.»

55 SANTOS VIJANDE, J. M.: «Caso Otegui: Inconsecuencia de Estrasburgo», en $A B C$ de 20 de junio de 2011, pág. 3.

56 STEDH de 27 de febrero de 2001, caso Jerusalem contra Austria, párrafo 43.

57 STEDH de 15 de marzo de 2011, caso Otegui contra España, párrafo 38.

58 Vid. STEDH supra, párrafo 57. 
cuando es una de las acusaciones más graves que pueden producirse dentro de una sociedad democrática?

Creemos sinceramente que las declaraciones de Otegui debieron ser consideradas por el TEDH como un ejemplo claro del denominado discurso del odio ${ }^{59}$, por las palabras utilizadas, por el contexto en el que se produjeron y por el sujeto que las pronunció ${ }^{60} \mathrm{y}$, por lo tanto, debieron quedar excluidas del ámbito de protección del Convenio, considerándose legítima la injerencia por parte del Estado español, no solo en defensa del honor de Don Juan Carlos, sino también en aras de mantener la paz social y un clima de seguridad nacional. Incluso el propio Tribunal ha manifestado en diversas ocasiones ${ }^{61}$ que «cabe restringir la libertad de expresión persiguiendo el fin legítimo de preservar la seguridad del Estado, especialmente cuando la restricción tiene lugar en un ambiente de actividad terrorista o, simplemente, favorable o predispuesto a la violencia, y cuando las manifestaciones restringidas sean capaces de provocar especial impacto, haciendo temer un incremento de los disturbios, porque procedan de personas que desempeñan un papel relevante en la actividad política» ${ }^{62}$.

No lo entendió así el Tribunal, que consideró que «aún cuando ciertos términos del discurso del demandante pintan una imagen de los más negativa del Rey en cuanto institución dando así al discurso una connotación hostil, sin embargo, no por ello exhortan al uso de la violencia, y no se trata de un discurso del odio» ${ }^{63}$. Con esta reflexión el TEDH ha dado muestras de su desconocimiento de la situación que se vive en el País Vasco y en el resto de España en relación con el problema del terrorismo. Por esta razón, creemos que erró al no respetar un mayor margen de apreciación de los Tribunales españoles, quienes, indiscutiblemente, tienen un conocimiento mayor y mejor del tema.

A nuestro juicio, lo que realmente llevó al TEDH a condenar a España fueron dos detalles relacionados con el caso: que la condena fuera penal y la pena impuesta de prisión - lo que consideró desproporcionado-, y que se produjera como consecuencia de un delito cuya existencia responde a «una protección ampliada del Jefe del Estado», algo que ha sido ampliamente criticado por dicho Tribunal y cuya desaparición se ha solicitado, a

59 Como destaca el Prof. Sánchez de Diego en su artículo citado, es curioso que el TEDH, en la sentencia, se refiera al discurso del odio pero no cite la recomendación $\mathrm{n}^{\circ} \mathrm{R}(97) 20$, sobre este mismo asunto, ni aluda a ninguno de los documentos del Consejo de Europa sobre terrorismo, cuando es un elemento esencial en este asunto y que debió tenerse en cuenta.

60 SÁNCHEZ DE DIEGO FERNÁNDEZ DE LA RIVA, M., op.cit. «las injurias al Rey....», en prensa, dice a este respecto: «Se trata de dos sujetos que se mueven en planos distintos, uno en el de la representación del Estado y el pueblo español, el otro en el de la confrontación política muy propia del nacionalismo independentista que precisa una agresión constante contra el Estado y sus instituciones para fomentar un sentimiento de exclusión y victimismo que movilice a los afines. (...) No nos encontramos ante una disputa política ordinaria (...). Sí que nos hallamos ante un conflicto con unas características diferenciales, en donde se produce una acción violenta asociada a una acción política con el objetivo de conseguir la ruptura constitucional».

61 STEDH de 25 de febrero de 1997, caso Zana contra Turquía; STEDH de 9 de julio de 1998, caso Incal contra Turquía; STEDH de 10 de julio de 1998, caso Sideropoulos contra Grecia.

62 SANTOS VIJANDE, J. M.: «Caso Otegui: Inconsecuencia de Estrasburgo», en $A B C$ de 20 de junio de 2011, pág. 3.

63 STEDH de 15 de marzo de 2011, caso Otegui contra España, párrafo 54. 
todos los países donde se mantiene este tipo de legislación, en reiteradas sentencias y en varios documentos del Consejo de Europa ${ }^{64}$.

En cuanto al hecho de que fuera condenado penalmente, cabe apuntar aquí, que si bien el TEDH se ha mostrado en muchas ocasiones contrario a las condenas penales en asuntos de libertad de expresión, y más aún a que las penas impuestas supusieran prisión, lo cierto es que el Tribunal ha reconocido que «es totalmente legítimo que las autoridades competentes, en su calidad de garantes del orden público institucional, protejan a las instituciones del Estado» ${ }^{65} \mathrm{y}$ ha llegado a admitir este tipo de castigo por como repuesta a una «necesidad social imperiosa». Así, por ejemplo, en el caso Zana contra Turquía, «Estrasburgo estimó que su condena a 12 meses de prisión no vulneraba la libertad de expresión dado «el derecho de las sociedades democráticas a protegerse de las organizaciones terroristas», y dado que la naturaleza de las declaraciones y su procedencia de una persona política «podían agravar una situación ya explosiva en la región». En consecuencia, apreció que la pena impuesta respondía a una «necesidad social imperiosa», como exige el Convenio de Roma» ${ }^{66}$.

Respecto a que la condena se produjera por considerar la conducta un delito tipificado en el art. 490.3 CP, «que otorga al Jefe de Estado un nivel de protección más alto que a otras personas (protegidas por el régimen común de la injuria), o Instituciones (tales como el Gobierno o el Parlamento)», el Tribunal reiteró «que ampliar la protección por medio de una Ley especial en materia de injurias no es, en principio, conforme con el espíritu del Convenio ${ }^{67}$. No discutiremos el hecho de que efectivamente la pena que se impuso en este caso es superior a la prevista en el supuesto de las injurias del art. 208 $\mathrm{CP}^{68}$, pero tampoco discutiremos el hecho de que si Otegui hubiera sido condenado en base al art. 208 CP (por inexistencia del art. 490 CP), la pena habría sido superior, por las declaraciones realizadas, porque en contra de lo que opina el TEDH, no fueron simplemente exageradas o provocadoras, como parece desprenderse del texto de la sentencia ${ }^{69}$, sino claramente injuriosas. Además, las declaraciones se emitieron por la televisión, un medio que, como ha dicho el TEDH en muchas ocasiones, tiene un impacto en la población mucho mayor que cualquier otro medio ${ }^{70}$. Coincidimos con la idea de que «la libertad de expresión no excluye la crítica a una institución constitucional», y que «es precisamente cuando se exponen ideas que molestan, ofenden y cuestionan el orden

$64 \mathrm{La}$ «Declaración sobre la libertad de discurso político en los medios de comunicación», de 12 de febrero de 2004 y la resolución n 1577 «Hacia la despenalización de la difamación», de 4 de octubre de 2007. Obsérvese, no obstante, que ambos documentos son posteriores a las declaraciones objeto del asunto que nos ocupa.

65 STEDH de 15 de marzo de 2011, caso Otegui contra España, párrafo 58.

66 SANTOS VIJANDE, J. M.: op.cit., pág. 3, en relación a la STEDH de 25 de febrero de 1997, caso Zana contra Turquía.

67 STEDH de 15 de marzo de 2011, caso Otegui contra España, párrafo 55.

68 La pena por injurias graves, según el art. 209 CP, será de multa de 6 a 14 meses si se hiciera con publicidad y de 3 a 7 meses en otro caso. La pena por injurias graves al Rey, según el art. 490.3 CP, será de prisión de 6 meses a 2 años.

69 STEDH de 15 de marzo de 2011, caso Otegui contra España, párrafo 54: «el Tribunal admite que el lenguaje utilizado por el demandante puede haberse considerado provocador. (...) se le permite recurrir a cierta dosis de exageración, incluso provocación, es decir, ser algo inmoderado en sus manifestaciones».

70 STEDH de 23 de septiembre de 1994, caso Jersild contra Dinamarca; STEDH 16 de abril de 1991, caso Purcel y otros contra Irlanda. 
establecido cuando la libertad de expresión es más valiosa» ${ }^{71}$, pero no hay que olvidar que la libertad de expresión no ampara el derecho al insulto.

Asi pareció entederlo también la abogacía del Estado español, ya que en el mes de junio de 2011 presentó una solicitud para que se elevara ante la Gran Sala del Tribunal de Estrasburgo, órgano de apelación, el caso que nos ocupa, al entender que dicho asunto planteaba importantes cuestiones que afectaban a la interpretación del Convenio Europeo de Derechos Humanos y que no habían sido resueltas. Así, solicitó que se examinase las consecuencias del ejercicio de la libertad de expresión por representantes electos versus la reputación de terceros, la responsabilidad de aquéllos cuando ejercen la libertad de expresión en un contexto de violencia ${ }^{72}$ y la protección de las Instituciones (en este caso del Rey) frente a las difamaciones.Rrecientemente, el 19 de septiembre, el órgano de apelación admitió la petición de España ratificando la condena a nuestro país.

Llegados a este punto solo nos queda reiterar que desde nuestro punto de vista el TEDH ha tratado de mantener, como norma general, una jurisprudencia lineal y coherente en relación a las injerencias en la libertad de expresión por parte de las autoridades nacionales. Esto puede apreciarse en la sentencia relativa al caso de José Luis Gutiérrez contra España, resolución con la que nos encontramos en total consonancia, aunque consideramos que habría sido conveniente que el TEDH se pronunciara sobre el hecho de que la condena al periodista se fundamentó en una ley de 1966. En el caso de Otegui contra España, por el contrario, nos mostramos en total desacuerdo, ya que la conclusión a la que llega el TEDH no nos parece en absoluto acertada. Cierto es que mantiene coherencia en cuanto a su oposición a que exista cualquier tipo de norma que refuerce la protección del honor de los Jefes de Estado en detrimento de la libertad de expresión, pero creemos que esta circunstancia le ha impedido ponderar otros factores. Pensamos que yerra al no tomar en consideración todos los elementos del contexto ${ }^{73}$ en que se producen las declaraciones del sujeto (las circunstancias especiales de Otegui y su relación con partidos políticos vinculados a ETA, el ambiente de violencia en el País Vasco marcado por el terrorismo y la Kale Borroka, el discurso constante del odio por parte de Otegui contra España y nuestras instituciones, etc...) y, que según su propia jurisprudencia podrían justificar una condena penal. El TEDH sólo tomó en consideración aquellos extremos que justificaban la defensa de la libertad de expresión del «representante político» obviando su propia doctrina sobre el contenido y consecuencias de cierto tipo de de-

71 Vid. STEDH supra, párrafo 56.

72 SETDH de 2 de octubre de 2008, caso Leroy contra Francia. En este caso, el TEDH hacía refencia a que cualquiera que pretende hacer prevalecer su derecho a la libertad de expresión, debe asumir los deberes y responsabilidades que devienen de tal ejercicio. Jurisprudencia que, por otro lado, no aplicó al caso de Otegui contra España.

73 GARCÍA ROCA, J.: «La muy discrecional doctrina del margen de apreciación nacional. Según el Tribunal Europeo de derechos Humanos: Soberanía e integración», en Teoría y Realidad Constitucional, núm. 20, 2007, págs. 128-129, dice: «¿Qué perspectiva es mejor: la próxima y nacional o la distante y europea? Un viejo problema de toda filosofía. Cómo alcanzar a la vez un distanciamiento de los hechos y un adecuado conocimiento de las complejas realidades nacionales. A menudo no se pueden tener ambas cosas (...) La distancia permite la serenidad del espíritu propia del juzgador imparcial. Pero un juicio sabio y constitucionalmente adecuado demanda conocer la realidad fáctica y normativa que se juzga y ello exige proximidad e inmediatez y conocimiento del Derecho nacional». 
claraciones que se producen en un ambiente viciado por el terrorismo. Consideramos, por tanto, que el Tribunal debió en este caso otorgar un mayor margen de apreciación ${ }^{73}$ a los Tribunales españoles — dado que en el caso concreto existían múltiples elementos que los justificaban-, así como aplicar su doctrina del discurso del odio, lo que habría dado lugar a una sentencia totalmente contraria.

$$
* * *
$$

TITLE: Freedom of speech in the jurisprudence of the European Court of Human Rights. Two Spanish cases

ABSTRACT: Freedom of speech is in every of its manifestations one the most important rights of human beings. That explains why it is considered as a preferred freedom, and granted protection against any kind of arbitrary interference on the part of public authorities. This concept, that we fully share, infuses the European Court jurisprudence, and it is supposed to permeate any case that comes under its consideration. The judgment in José Luis Gutiérrez v. Spain was a good example in that sense; but the ruling in Otegui v. Spain did not meet the logical expectations. In our opinion, the Court should have regarded Otegui's announcement as a clear signal of 'bate speech', and as such, without the protection of article 10 of the Convention.

RESUMEN: La libertad de expresión —en todas sus vertientes — es, sin lugar a dudas, uno de los derechos más relevantes con el que cuenta el ser bumano, por lo que debe configurarse como un derecho prevalente y su protección estar asegurada frente a cualquier tipo de injerencia arbitraria por parte de las autoridades. Esta línea argumental, cuya esencia compartimos, parece ser la mantenida por el TEDH en su jurisprudencia, y trata de aplicarse a los casos expuestos manteniendo una línea de coherencia con las sentencias dictadas anteriormente por el Tribunal. Así ocurre, desde nuestro punto de vista, en el caso de José Luis Gutiérrez contra España, pero no en el de Otegui contra España. En este último caso, consideramos que el TEDH debió considerar las declaraciones de éste como «discurso del odio»y, por tanto, exentas de protección al amparo del art. 10 del Convenio.

KeYwOrds: Human rights. Freedom of expression. Reputation. Truthfulness. Public interest. Hate speech.

Palabras Clave: Derechos humanos. Libertad de expresión. Honor. Veracidad. Interés público. Discurso del odio.

FeCHA DE RECEPCIÓN: 14.07.2011. FeCHA DE ACEPTACIÓN: 29.07.2011.

74 MCHONEY, P., CALLEWAERT, J., WINISDOERFFER, Y., y otros: «The Doctrine of Margin of Appreciation under the European Convention on Human Rights: Its legitimacy in Theory and Application in practice», en Human Rigtbs Journal, vol. 19, núm. 1, 1998, págs. 1-36. 